\title{
Inhibitor Design for Human Heat Shock Protein 70 ATPase Domain by Pharmacophore-based in silico Screening
}

\author{
Jee-Young Lee, Ki-Woong Jung, and Yangmee Kim* \\ Deparment of Bioscience and Biotechnologv, Biol Holectuar Informatics Center, Konkuk Lniversitv, Seoul 143-701, Korea \\ ${ }^{*}$ E-mail: wmkimakonkuk.ac.kr \\ Received Juhe 25, 2008
}

\begin{abstract}
The $70 \mathrm{kDa}$ heat-shock protein ( $\mathrm{Hsp} 70$ ) involved in various cellular functions. such as protein folding. translocation and degradation. regulates apoptosis in cancer cells. Recently, it has been reported that the green tea flavonoid (-)-epigallocatechin 3-gallate (EGCG) induces apoptosis in mumerous cancer cell lines and could inhibit the anti-apoptotic effect of human Hsp70 ATPase domain (hATPase). In the present study. docking model between EGCG and hATPase was determined using automated docking study. Epi-gallo moiety in EGCG participated in hydrogen bonds with side chain of $\mathrm{K} 71$ and T204, and has metal chelating interaction with hATPase. Hydroxyl group of catechin moiety also participated in metal chelating hỵdrogen bond. Gallate moiety had two hyddrogen bondings with side chains of E268 and K271, and hydrophobic interaction with Y 15. Based on this docking model. we determined two pharmacophore maps consisted of six or seven features. including three or four hydrogen bonding acceptors. two hydrogen bonding donors. and one lipophilic. We searched a flavonoid database including 23 naturally occurring flavonoids and 10 poly phenolic flavonoids with two maps. and myrricetin and GC were hit by map I. Three hydroxyl groups of B-ring in myricetin and gallo moiety of GC formed important hydrogen bonds with hATPase. 7-OH of A-ring in myricetin and $\mathrm{OH}$ group of catechin moiety' in GC are hỵ'drogen bond donors similar to gallate moiety' in EGCG. From these results. it can be proposed that myricetin and GC can be potent inhibitors of hATPase. This study will be helpful to understand the mechanism of inhibition of hATPase by EGCG and give insights to develop potent inhibitors of hATPase.
\end{abstract}

Key Words : EGCG. Hsp 70, Flavonoids, Anticancer drug. In silico screening

\section{Introduction}

(-)-Epigallocatechin 3-gallate (EGCG) is a major catechin in green tea. Catechin is a representative flavonol related biological regulation. ' Activity of EGCG against various diseases is well known. For example. EGCG has an antioxidative effect that helps protect the skin from UV radiation induced damage and an effect of remitting multiple sclerosis. ${ }^{23}$ EGCG has a significant effect against tumorigenesis and tumor growth by selectively induced apoptosis in various cancer cell-lines. ${ }^{4.5}$ Recently it has been reported that EGCG was found to bind the Hsp 70. ' glucose regulated protein 78 (Grp 78)' thus inhibiting its antiapoptotic actions. ${ }^{4-6}$

The $70 \mathrm{kDa}$ heat-shock proteins (Hsp 70 ) are a family of molecular chaperones. which promotes various cellular functions. such as protein folding. translocation and degradation. $^{7-9}$ In normal conditions. Hsp 70 functions as an ATP-dependent chaperon by assisting the folding of newly synthesized proteins and polypeptides. the assembly of multiprotein complexes and the transport of proteins across cellular membranes. In contrast. its upregulation. as a consequence of either cellular stress or transfection. inhibits the induction of apoptosis by several insults and may contribute to oncogenic transformation. ${ }^{10.11}$ Over-expression of Hsp 70 inhibits the apoptosis which is also characterized by caspaseindependent processes. ${ }^{10.11}$ The antiapoptotic function of Hsp70 involves interactions with several components of the apoptotic machinery. ${ }^{12}$ Metal ions are among the stimuli that affect the transcription of some chaperone proteins like Hsp $70 .{ }^{13}$ In addition. these proteins need metal ions for ATP binding and hỵdrolỵsis. and for chaperone activity.

Human $\mathrm{Hsp} 70$ is a 640 amino acid protein composed of two major domains. N-terminal ATPase domain of $\mathrm{Hsp} 70$ binds to and hydrolyzes ATP, whereas the C-terminal domain is required for polypeptide binding ${ }^{13}$ The crystal structure of human Hsp70 ATPase domain (hATPase) has been determined by x-ray cry stallography. ${ }^{13}$ EGCG might inhibit the antiapoptotic activity of $\mathrm{Hsp} 70$ by competing with adenosine triphosphate (ATP) for binding to the hATPase but the mechanism of this action is not clear.

Here, in order to understand the interactions between hATPase and EGCG automated docking study was performed and a docking model between hATPase and EGCG was proposed. Furthermore. we determined a pharmacophore map by receptor-oriented pharmacophore-based in silico screening and screened potent flavonoids inlibitors of hATPase.

\section{Methods}

Docking Study, Docking model between EGCG and Hsp 70 was determined by AutoDock ${ }^{1+16}$ in order to find specific binding model based on the x-ray structure of hATPase (1S3X.pdb and 2E8A.pdb). ${ }^{13}$ The Lamarckian 
Genetic Algoritlun (LGA) of the AutoDock 3.05 was used for docking experiments. MD simulations on the final docking structure were performed in the canonical ensemble $(\mathrm{NVT})$ at $300 \mathrm{~K}$ and distance-dependent function of the dielectric constant was used for the calculation of the energetic maps in vacuum system using the program lnsightll/ Discover. All atoms of the system were considered explicitly. and their interactions were computed using the consistent valence force field. A distance cutoff of $10 \AA$ was used for van der Waals interactions and electrostatic interactions. The time step in the MD simulations was $1 \mathrm{fs}$ and MD simulation was performed for 2 ns. Coordinates were saved every $1 \mathrm{ps}$. The average structure was calculated for the 2 ns trajectory and submitted to funal energy minimization by performing 10,000 steps of steepest descent method.

Receptor-oriented Pharmacophore-based in silico Screening. The interaction model used for this process is a list of features: lydrogen bonds and lipophilic interactions. These features include hydrogen bond donors (HBDs). hydrogen bond acceptors (HBAs) and lipophilicity (lipo). Pharmacophore maps were generated with the excluded volume for the heavy atoms. The exclusion volume is the forbidden area in the active site. which defines its shape. To account for excluded volume regions occupied by the heavy atoms in the receptor, an exclusion model is generated for the active site and the surrounding receptor regions. Each atom of the receptor selected for inclusion in the model is represented as an exclusion point. This procedure was performed using SBF (structure-based focusing) module in Cerius2 (Accelrys, San Diego. USA).

Active site of Hsp 70 ATPase domain was defined around the center of the EGCG and an interaction model was generated within $11 \AA$ from the center of the active site. Multiple pharmacophore maps were determined with six or seven features for each map. The exclusion volume was built from the heavy atons within $11 \AA$ from the center of the active site. We selected the proper phannacophore map which reproduced the docking model of EGCG and Hsp70. We built a flavonoid database which included twenty three naturally-occurring flavonoids and ten catechin based polyphenolic flavonoids extracted from green and black tea. Twenty three naturally-occurring flavonoids were collected considering subclass of flavonoids (flavones. flavonols. flavonones. and isoflavones) and are listed in Table 1. The structures of poly phenolic flavonoids are shown in Figure 1. This database was browsed using selected pharmacophore maps. The scoring functions (LigScore2. PLP1. and PLP2) were calculated for hits to establish a relationship between this pharmacophore and the set of inhibitors using Cerius2. ${ }^{17.18}$

\section{Results and Discussion}

Analysis of the X-ray Structure of hATPase-ADP Complex. Several crystal structures of ATP family compounds (ADP or ANP) bound to ATPase domain of Hsp70 have been reported ${ }^{13,19}$ Metal ions affect the transcription of some
Table 1. Classification of flavonoids based on the position of their substituent

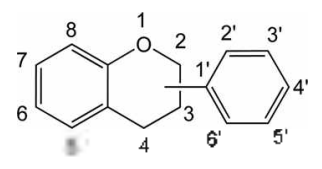

\begin{tabular}{|c|c|c|c|c|c|c|c|c|}
\hline \multirow{2}{*}{\multicolumn{2}{|c|}{ Class of Flavonoids }} & \multicolumn{7}{|c|}{ Position of Substituent's } \\
\hline & & \multirow{2}{*}{$\frac{3}{\mathrm{H}}$} & \multirow{2}{*}{$\frac{5}{\mathrm{OH}}$} & \multirow{2}{*}{$\frac{7}{\mathrm{OH}}$} & \multirow{2}{*}{$\frac{2^{\prime}}{\mathrm{H}}$} & \multirow{2}{*}{$\begin{array}{l}3^{\prime} \\
\mathrm{H}\end{array}$} & \multirow{2}{*}{$\frac{4}{H}$} & \multirow{2}{*}{$\begin{array}{l}5^{\prime} \\
\mathrm{H}\end{array}$} \\
\hline Flavones & Chrysin & & & & & & & \\
\hline & Techtochry sirl & $\mathrm{H}$ & $\mathrm{O}-\mathrm{Me}$ & $\mathrm{OH}$ & $\mathrm{H}$ & $\mathrm{H}$ & $\mathrm{H}$ & $\mathrm{H}$ \\
\hline & Baicalein & $\mathrm{H}$ & $\mathrm{OH}$ & $\mathrm{OH}$ & $\mathrm{H}$ & $\mathrm{H}$ & $\mathrm{H}$ & $\mathrm{H}$ \\
\hline & Apigenir & $\mathrm{H}$ & $\mathrm{OH}$ & $\mathrm{OH}$ & $\mathrm{H}$ & $\mathrm{H}$ & $\mathrm{OH}$ & $\mathrm{H}$ \\
\hline & Luteolin & $\mathrm{H}$ & $\mathrm{OH}$ & $\mathrm{OH}$ & $\mathrm{H}$ & $\mathrm{OH}$ & $\mathrm{OH}$ & $\mathrm{H}$ \\
\hline & Diosmetirl & $\mathrm{H}$ & $\mathrm{OH}$ & $\mathrm{OH}$ & $\mathrm{H}$ & $\mathrm{OH}$ & $\mathrm{O}-\mathrm{Me}$ & $\mathrm{H}$ \\
\hline & Tangeretin & $\mathrm{H}$ & $\mathrm{O}-\mathrm{Me}$ & $\mathrm{O}-\mathrm{Me}$ & $\mathrm{H}$ & $\mathrm{H}$ & $\mathrm{O}-\mathrm{Me}$ & $\mathrm{H}$ \\
\hline \multirow[t]{8}{*}{ Flavonols } & Galangin & $\mathrm{OH}$ & $\mathrm{OH}$ & $\mathrm{OH}$ & $\mathrm{H}$ & $\mathrm{H}$ & $\mathrm{H}$ & $\mathrm{H}$ \\
\hline & Kaempferol & $\mathrm{OH}$ & $\mathrm{OH}$ & $\mathrm{OH}$ & $\mathrm{H}$ & $\mathrm{H}$ & $\mathrm{OH}$ & $\mathrm{H}$ \\
\hline & Quercetirl & $\mathrm{OH}$ & $\mathrm{OH}$ & $\mathrm{OH}$ & $\mathrm{H}$ & $\mathrm{OH}$ & $\mathrm{OH}$ & $\mathrm{H}$ \\
\hline & Myricetin & $\mathrm{OH}$ & $\mathrm{OH}$ & $\mathrm{OH}$ & $\mathrm{H}$ & $\mathrm{OH}$ & $\mathrm{OH}$ & $\mathrm{OH}$ \\
\hline & Fisetin & $\mathrm{OH}$ & $\mathrm{H}$ & $\mathrm{OH}$ & $\mathrm{H}$ & $\mathrm{OH}$ & $\mathrm{OH}$ & $\mathrm{H}$ \\
\hline & Morin & $\mathrm{OH}$ & $\mathrm{OH}$ & $\mathrm{OH}$ & $\mathrm{OH}$ & $\mathrm{H}$ & $\mathrm{OH}$ & $\mathrm{H}$ \\
\hline & Kaempferide & $\mathrm{OH}$ & $\mathrm{OH}$ & $\mathrm{OH}$ & $\mathrm{H}$ & $\mathrm{H}$ & $\mathrm{OMe}$ & $\mathrm{H}$ \\
\hline & Khamuetin & $\mathrm{OH}$ & $\mathrm{OH}$ & $\mathrm{O}-\mathrm{Me}$ & $\mathrm{H}$ & $\mathrm{OH}$ & $\mathrm{OH}$ & $\mathrm{H}$ \\
\hline \multirow[t]{5}{*}{ Flavonones } & Pinocembrin & $\mathrm{H}$ & $\mathrm{OH}$ & $\mathrm{OH}$ & $\mathrm{H}$ & $\mathrm{H}$ & $\mathrm{H}$ & $\mathrm{H}$ \\
\hline & Naringenin & $\mathrm{H}$ & $\mathrm{OH}$ & $\mathrm{OH}$ & $\mathrm{H}$ & $\mathrm{H}$ & $\mathrm{OH}$ & $\mathrm{H}$ \\
\hline & Errodictyol & $\mathrm{H}$ & $\mathrm{OH}$ & $\mathrm{OH}$ & $\mathrm{H}$ & $\mathrm{OH}$ & $\mathrm{OH}$ & $\mathrm{H}$ \\
\hline & Hesperitin & $\mathrm{H}$ & $\mathrm{OH}$ & $\mathrm{OH}$ & $\mathrm{H}$ & $\mathrm{OH}$ & $\mathrm{O}-\mathrm{Me}$ & $\mathrm{H}$ \\
\hline & Taxitolin & $\mathrm{OH}$ & $\mathrm{OH}$ & $\mathrm{OH}$ & $\mathrm{H}$ & $\mathrm{OH}$ & $\mathrm{OH}$ & $\mathrm{H}$ \\
\hline \multirow[t]{3}{*}{ Isotlavones } & Genistein & - & $\mathrm{OH}$ & $\mathrm{OH}$ & $\mathrm{H}$ & $\mathrm{H}$ & $\mathrm{OH}$ & $\mathrm{H}$ \\
\hline & Genistin & - & $\mathrm{OH}$ & $\mathrm{O}$-cilul & $\mathrm{H}$ & $\mathrm{H}$ & $\mathrm{OH}$ & $\mathrm{H}$ \\
\hline & Daidein & - & $\mathrm{H}$ & $\mathrm{O}$-Glu & $\mathrm{H}$ & $\mathrm{H}$ & $\mathrm{OH}$ & $\mathrm{H}$ \\
\hline
\end{tabular}

-O-Me = Methoxy $\quad$-O-Glu = Glucosyl $\quad-\mathrm{O}-\mathrm{R}^{\prime}=$ Alkoxy

chaperone proteins such as $\mathrm{Hsp} 70$, and these proteins need metal ions for ATP binding and hydrolysis. and for chaperone activity. ${ }^{3 j-23}$ In the ATP-binding site of Hsp70. two calcium ions are included. One corresponds to the catalytic site in hATPase and appears to be important for ATP hydrolysis and in vitro phosphorylation. ${ }^{13}$ Local changes in protein structure as a result of calcium binding may facilitate phosphorylation. The second calcium site represents a new calcium binding motif that can play a role in the stabilization of protein structure and does not have interactions with ADP. Second calcium ion was found on the surface of protein and formed salt bridges with E231 and D232. ${ }^{13}$ The two calcium binding sites of hATPase are presented in Figure 2. In the ADP binding site the interactions between ADP and hATPase included complicated hydrogen bonding network. The ribose hydrogen of ADP bonds to the side chain of E268 and $\mathrm{K} 271$ and $\beta$-phosphate forms a salt bridge with calcium ion. The x-ray structure of hATPase is containing ADP and free phosphate $(\mathrm{Pi})$ group. The $\mathrm{Pi}$ group fonns a salt bridge with K71 and makes hydrogen bonds with T13 and T204. The binding model between ADP/Pi and hATPase is shown in Figure 2(B).

Study on Docking between EGCG and hATPase. The 
(A)

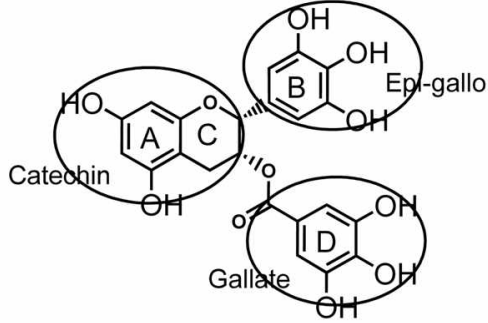

(-)-Epigallocatechin gallate (EGCG)<smiles>O=C(COc1cc(O)cc(O)c1)C(=O)C1Cc2c(O)cc(O)cc2O[C@H]1c1cc(O)c(O)c(O)c1</smiles>

(+)-Gallocatechin-3-gallate (GCG)

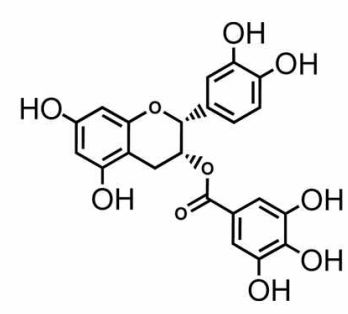

(-)-Epicatechin gallate (ECG)<smiles></smiles>

(+)-Catechin (C)<smiles>Oc1cc(O)c2c(c1)O[C@@H](c1cc(O)c(O)c(O)c1)[C@@H](O)C2</smiles>

(+)-Gallocatechin (GC)<smiles>Oc1ccc(C2COc3cc(O)cc(O)c32)c(O)c1</smiles>

(-)-Epicatechin (EC)<smiles>Oc1cc(O)c2c(c1)O[C@H](c1cc(O)c(O)c(O)c1)[C@H](O)C2</smiles>

(-)-Epigallocatechin (EGC)

(B)

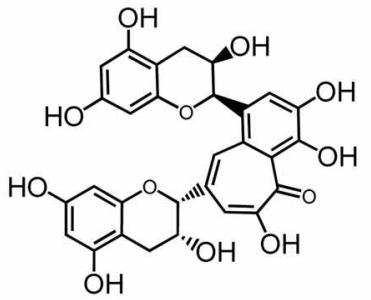

Theaflavin

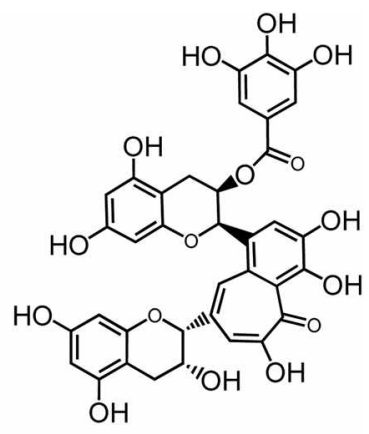

Theaflavin-3-gallate

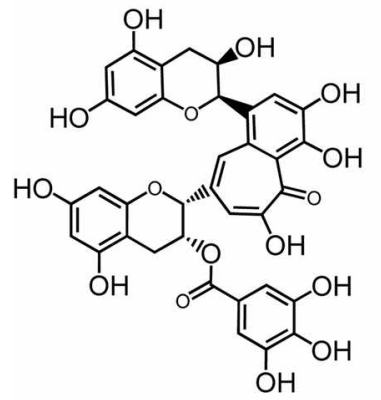

Theafkavin-3'-gallate

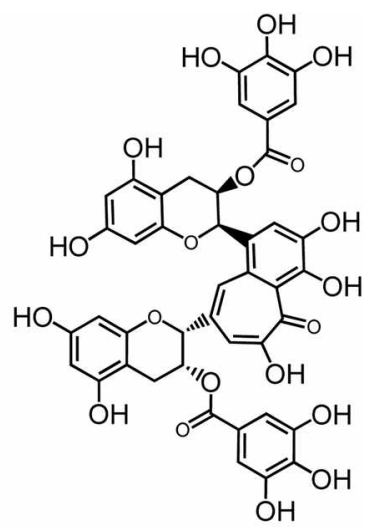

Theaflavin-3,3'-gallate

Figure 1. Chemical structures of catechin based flavonoids. (A) EGCG tamily flavonoids extracted from green tea. (B) Theaflavin family flavonoids from black tea.

(A)

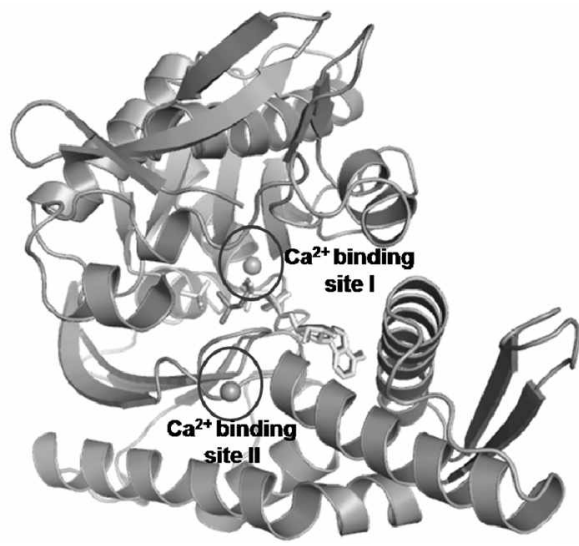

(B)

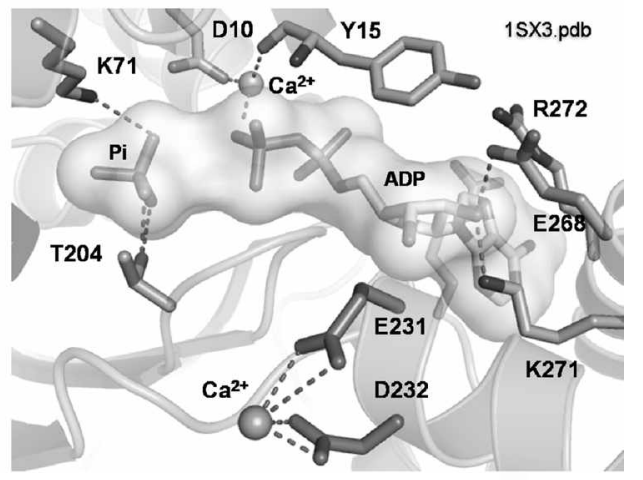

Figure 2. (A) Crystal structure of hATHase (B) ADP binding site of hATPase showing the hydrogen bonds with ADP and free phosphate.

interactions of EGCG and hATPase were similar to that in $\mathrm{X}$-ray structures of hATPase complex with ADP, and similar pattens of hỵdrogen bonds are also found in our docking model.

Structure of EGCG is divided into three chemical groups. such as catechin ( $\mathrm{A}-\mathrm{C}$ ring), epi-gallo (B-ring). and gallate (D-ring) moieties. as shown in Figure 1. Three hyddroxyl groups of epi-gallo in EGCG participated in hydrogen bonding interactions with side chain of K71. T204, and had metal mediated hydrogen bonding with Y15. In addition. one more metal chelated hydrogen bonding interaction was formed with hydrosyl group of catechin moiety. This propensity could promote the strong binding interaction with hATPase ${ }^{2+}$ Gallate group formed two hydrogen bonding interactions with side chain of E268 and K27l. and hydrophobic interaction with Y15. It is already known that the 
(A)

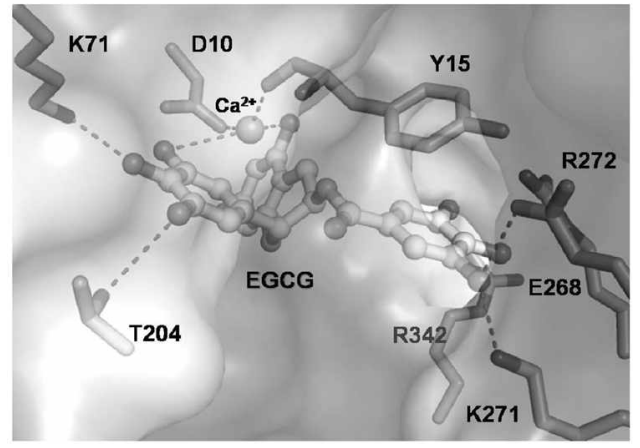

(B)

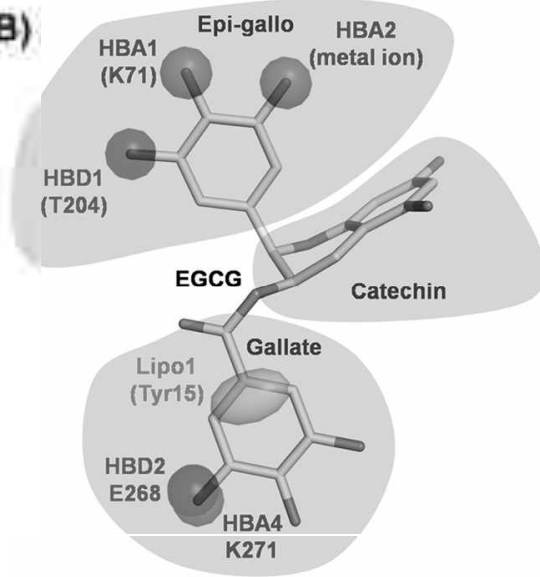

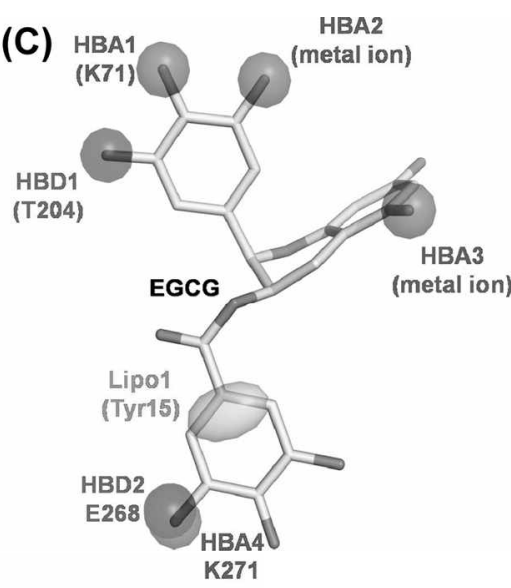

Figure 3. (A) Docking model of d hATPase with EGCG. Optimal phamacophore map I (B) and map II (C).

hydrogen bond between inhibitor and K7l has significant effect to hydrolyze ATP. ${ }^{13,35}$ The interaction model between EGCG and hATPase is shown in Figure 3. From docking study. we confinmed that EGCG and hATPase formed specific and tight hydrogen bonding interactions.

Receptor-oriented Pharmacophore-based in silico Screening. Two pharmacophore maps were determined based on the hydrogen bonding interactions and hydrophobic interactions between EGCG and hATPase. Map I consisted of six features: HBAI (K7l), HBA2 $\left(\mathrm{Ca}^{3+}\right)$. $\mathrm{HBA} 4$ (K271). HBDI (T204), HBD2 (E268), and Lipol (Y15). Map II included seven features and one more feature (HBA4) was added. HBA2 depicted a metal chelating interaction with epi-gallo moiety, while $\mathrm{HBA} 4$ represented an additional metal chelation with catechin moiety of EGCG Map I described tightly the interactions between ADP and hATPase. while Map II represented the interactions between EGCG and hATPase. Two phannacophore maps are shown in Figure 3

The database of compounds screened in the current in silico study includes 23 well known naturally occurring flavonoids listed in Table 1 and 10 polyphenolic flavonoids extracted from green and black tea shown in Figure 1. Green and black teas are two major types of tea manufactures from the leaves of the plant Camellia sinesis ${ }^{30}$ Six catechin based flavonoids are the major products in green tea. Theaflavins are flavan-3-ols that are found from catechins in tea leaves during the enzymatic oxidation of tea leaves. or those in black tea. Biological activities of these polyphenolic flavonoids against various human diseases are already known. ${ }^{36.25}$

From the in silico screening, only two flavonoids, myricetin and GC ((+)-Gallocatechin). were hit by map I. Hit models of myricetin and GC are very similar to each other. Myricetin is a flavonol found in grapes. berries fruits. vegetables and herbs. ${ }^{\text {ys }}$ Hit model of myricetin satisfied each features of pharmacophore map with proper configurations. Three hydroxyl group of B-ring of myricetin participated in hyydrogen bonding interaction with K71. T204. and in metal chelating interaction. B-ring of myricetin play's a role similar to epi-gallo moiety of EGCG 7-OH of myri-
Table 2. LigScore2 and PLP scores of known substrates and flavonoids

\begin{tabular}{cccc}
\hline Compound & LigScore2 & PLPl & PLP2 \\
\hline ADP & 7.14 & 144.0 & 142.3 \\
EGCG & 7.30 & 151.3 & 153.6 \\
Myricetir & 7.05 & 135.1 & 128.8 \\
GC & 7.11 & 136.4 & 130.5 \\
\hline
\end{tabular}

cetin also formed hydrogen bonds with the side chain of E268 and K271. Interaction model between myricetin and hATPase are shown in Figure 4A. Among 23 flavonoids. only myricetin has hydroxyl group of $5^{\prime}$-position. 5'-OH group participated in metal mediated lydrogen bonding interaction with hATPase. $3^{\prime} \cdot 4^{\prime} .5^{\prime}-\mathrm{OH}$ of flavonoids are necessary for the tight and specific hydrogen bonding interactions with lLATPase similar to those between EGCG and hATPase.

GC $((+)$-Gallocatechin) is one of the catechin based flavonoids extracted from green tea. Since GC has a gallo group. it formed two hydrogen bonds with K71 and T204, and had metal chelating interaction with Y15 as shown in Figure 4B. Hy'droxyl group of catechin moiety participated in hydrogen bonding interaction with the side chain of E268 and K271 Although EC ((-)-Epigallocatechin). a stereo isomer of GC. also has a gallo group similar to $\mathrm{GC}$. gallo group of $\mathrm{EC}$ could not form hydrogen bonds with hATPase because of the steric hinderance problem caused by the stereo structure. Comparisons of the structure of EGCG and its derivatives indicate that the presence of the epi-gallo moiety on the $\mathrm{B}$ ring is necessary for the tight metal mediated binding to hATPase and the presence of the gallate moiety is also important for hydrophobic and hydrogen bonding interactions with hATPase. Other catechin based polyphenolic flavonoids shown in Figure 1 could not satisfy the pharmacophore maps because of the improper stereochemical structures or lack of gallate moiety.

Evaluation of the Docking Study. In order to verify the results of the docking study, we calculated scoring functions: LigScore2. PLP1. and PLP2. The LigScore2 is a scoring 
(A)

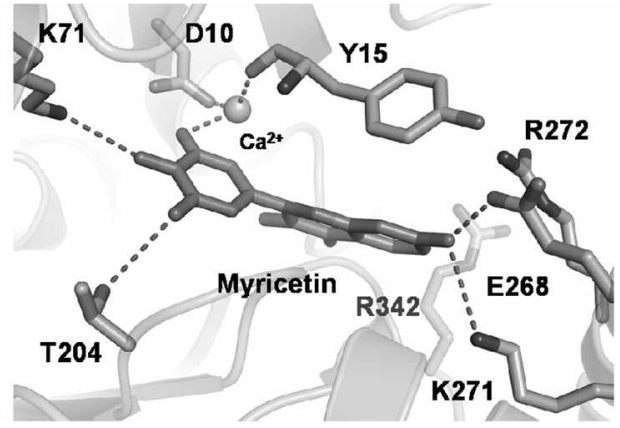

(B)

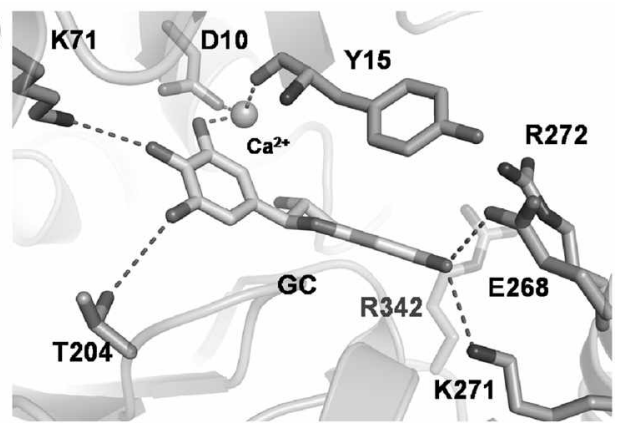

Figure 4. (A) Binding model of hATPase with myricetin. (B) Binding model of hATPase with GC.

function that possesses high predictive accuracy of affinity of ligand-receptor binding as well as $p K_{i}$ values. ${ }^{17}$ The PLP (Piecewise Linear Potential) is an empirical scoring function with two types. PLPI and PLP2. In the PLPl function, each non-hydrogen ligand or non-hydrogen receptor aton is assigned as PLP aton types. In both PLP functions, the higher PLP score indicates the stronger binding affinity with the receptor. ${ }^{18}$ EGCG gives higher score values than the known substrate ADP and this iniplied that EGCG can be a stronger substrate for hATPase than ADP. The competitive binding of EGCG to the Hsp70 ATPase domain was assessed using ATP-agarose. a dot blot and chemiluminescence techniques. ${ }^{5}$ The dot blot suggested $200 \mu \mathrm{M}$ EGCG competed with ATP for binding to Hsp70, presumably by binding its ATPase domain. inplying this flavonoid could inhibit the antiapoptotic effect of $\mathrm{Hsp} 70$. High scoring values in Table 2 inply that myricetin and GC also can be potent inhibitors for hATPase. Scoring functions. especially PLP I and 2 proved that automated docking process for EGCG and hATPase was performed well and the docking model represented the critical features for inhibitors of hAPTase suitably.

\section{Conclusion}

From automated docking study. we modeled a docking pose between EGCG and hATPase. Based on the docking model. we determined the multiple pharmacophore maps using by receptor-oriented pharmacophore-based in silico screening and determined two maps consisted of six or seven features: three or four HBA. two HBD and one Lipo. We built a flavonoids database included 23 normal flavonoids and 10 catechin based polyphenolic flasonoids and searched this database with determined pharmacophore maps. From the results of docking study and receptororiented pharmacophore based in silico screening. it can be proposed that myricetin and GC can be potent inhibitors of hATPase. Three hydrosyl group of B-ring in myricetin and gallo group of GC formed important hydrogen bonds similar to epi-gallo moiety of EGCG $7-\mathrm{OH}$ of A-ring in myricetin and $\mathrm{OH}$ group of catechin moiety in GC participated in hỵdrogen bonding interactions with E268 and K271 of hATPase. From these results. we suggested that a flavonol "myrricetin" and a polyphenolic flavonoids "GC" can be potent inhibitors of hAPTase and effective anticancer dnugs by suppression of antiapoptotic activity: This study may provide a strategy for the development of novel hAPTase inhibitors as apoptosis inducing anticancer drugs.

Acknowledgments. This work was supported by the Research Program for New Drug Target Discovery (M10601000153-07N0100-15310) grant from the Ministry of Science \& Teclunology, South Korea and by Bio/Molecular Informatics Center of Konkuk University (KRF-2006-005$\mathrm{J} 03402$ ). Ki-Woong Jung is supported. in part, by the second BK2l (MOE).

\section{References}

1. Chen1. D.: Milacic. V.: Chen. M. S.: Wan1. S. B.: Lam. W. H.: Huo. C.: Landis-Piwowar. K. R.: Cui. Q. C.: Wali. A.: Chan. T. H.: Dou. Q. P. Histol. Histopathol 2008. 23. 487.

2. Katiyar. S. K.: Matsui, M. S.; Elmets. C. A.: Mukhtar, H Photochem. Photobiol 1999, 69, 148.

3. Xu. Z.: Chen. S.: Li. X.: Luo. G.: Li. L.: Le. W. Newochem Res. 2006. 31. 1263.

4. Qanungo. S.: Das. M.: Haldar. S.: Basu. A. Corinogenesis 2005. 26.958 .

5. Brierley-Hobson, S. Bioscience Horizons 2008. 1,9.

6. Ermakova S. P.: Kang. B. S.: Choi. B. Y.: Choi. H. S.: Schuster. T. F.: Ma, W. Y.: Bode. A. M.: Dong. Z. Cancer Res. 2006, 66. 9260.

7. Aghdassi. A.: Phillips. P.: Dudeja. V: Dhaulakhandi. D.: Sharif. R.: Dawra. R.: Lerch. M. M.: Saluja. A. Cancer Res. 2007. 67. 616.

8. Nishikana, H.: Wakano. K, Kitani, S. Biochem. Bioplns. Res. Conmun. 2007, 362, 504 .

9. Bar-Shai. M.; Reznick, A. Z. Antoxid Redox Signal 2006. 8.639.

10. Ravagntan. L.: Gurbuxani. S.: Susin. S. A.: Maisșe. C.: Daugas. E.: Zamzani. N.: Mak. T.: Taattela. M.: Penninger. J. M.: Garrido. C.: Kroemer. G. Nat. Cell, Biol. 2001. 3. 839.

11. Gurbuxani, S.: Schmitt, E.: Cande. C.; Parcellier. A.; Hammann. A.; Daugas, E.: Kouranti. 1.: Spahr, C.; Pance. A.: Kroemer, G: Garrid, C. Oncogene 2003, 22. 6669.

12. Schmitt. E.: Parcellier. A.: Gurbuxani. S.: Cande. C.: Hammann. A.: Morales. M. C.: Hunt. C. R.: Dis. D. T.: Kroemer. R. T. Giordanetto. F.: Taattela. M.: Penninger. J. M: Pance. A: Kroemer. G.: Garrido. C. Cancer Res. 2003, 63, 8233.

13. Sriram, M.: Osipiuk. J.; Freeman, B.; Morimoto. R.: Joachimiak. A. Structure. 1997.5, 403.

14. Lee. J. Y.: Lee. S. A.: Kiml. Y. bull Korean Chem. Soc 2007. 28. 941.

15. Lee. T. Y: Baek. S.: Kim. Y. Bull. Korem Chem Soc. 2007. 28.379

16. Morris, G. M: Goodsell, D. S:- Halliday, R. S.; Huey R:- Hart, W. E.: Belew. R. K. Olson, A. J. d. Computational Chemisty 1998. 19. 1639 . 
17. Krammer. A.: Kirchhoff. P. D.: Venkatachalam. X. J. C. M.: Waldman. M. J. Mol. Graph. Model. 2005. 23.395.

18. Verkhivker. G. M.: Bouzida. D.: Gellhaar. D. K.: Rejto. P. A.: Arthurs. S.: Colson. A. B.: Freer. S. T.: Larson, V.: Lutvi. B. A.: Marrone, T: Rose. P. W. Jom of Computer Aided Holectlar Design 2000. 14,731.

19. Osipiuk. J.: Walsh. M. A.: Freeman. B. C.: Morimoto. R. I.: Joachimiak. A. Acta Crystallogr: D Biol. Costallogr. 1999. 55. 1105 .

20. Hatayama, T.: Asai, Y: Wakatsuki, T; Kitamura, T:; Inahara, $H$. J. Biochem. 1993. 114. 592.

21. Yamamoto, N.: Smith, M. W: Maki, A.: Berezeshy. I. K: Trump, B. F. Kidnev Int 1994. 15. 1093

22. Resendez. E.: Jr. Ting. J.: Kim. S.: Wodden. S. K.: Lee. A. S. $J$.
Cell. Biol. 1986. 103.2145.

23. Tillman. I. B.: Mote. P. L.: Walford. R. L.: Spindler. S. R. Gene 1995. 158.225.

24. Chen. L.: Zhang. H. Y. Holecules 2007. 12.946.

25. O'Brien. M. C.: Flaherty, K. M. McKay, D. B. J. Biol. Chem. 1996. 271,15874 .

26. Leone. M.: Zhai. D.: Sareth. S.: Kitada. S.: Reed. T. C.: Pellecchia. M. Cancer Res. 2003.63.8118.

27. Khan. N.: Afaq. F.: Saleem. M.: Ahmad. N.: Mukihtar. H. Cancer Res. 2006, 66, 2500 .

28. Chung. J. Y.: Huang, C.: Meng. X.; Dong. Z; Yang, C. S. Cancer Res. 1999, 59,4610.

29. Rzadkowska-Bodalska. H.: Olechnowicz-Stepiein. W. Pol. J. Pharntacol Phom. 1975. 27.345. 